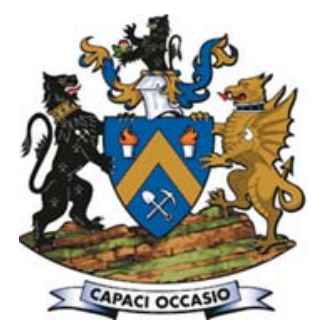

\title{
Recycling pre-oxidized chromite fines in the oxidative sintered pellet production
} process

\author{
by S.P. du Preez*, J.P. Beukes*, D. Paktunc`, P.G. van Zyl*, \\ and A. Jordaan*
}

\section{Synopsis}

The chromium $(\mathrm{Cr})$ content of stainless steel originates from recycled scrap and/or ferrochrome ( $\mathrm{FeCr}$ ), which is produced mainly by the carbothermic reduction of chromite ore. The oxidative sintered pellet production process is one of the most widely applied FeCr processes. The supplier of this technology specifies that recycling of chromite-containing dust collected from the pellet sintering off-gas and fines screened out from the sintered pellets (collectively referred to as pre-oxidized chromite fines) should be limited to a maximum of $4 \mathrm{wt} \%$ of the total pellet composition. However, the results presented in this paper suggest that recycling of such fines up to a limit of $32 \mathrm{wt} \%$ of the total pellet composition may improve the compressive and abrasion strengths of the cured pellet. In addition, electron microprobe and quantitative X-ray diffraction (XRD) analyses demonstrate that chromite grains present in the pre-oxidized chromite fines consist, at least partially, of crystalline phases/compounds that will improve the metallurgical efficiency and specific electricity consumption (i.e. MWh/ton FeCr produced) of the smelting process.

Keywords

Chromite, ferrochrome, ferrochromium, pre-oxidation, oxidative sintering, recycling.
According to this review, $\mathrm{FeCr}$ is principally produced in (i) conventional open/semi-closed submerged arc furnaces (SAFs) that are mainly fed with lumpy (typically $6-150 \mathrm{~mm}$ ) chromite ore, fluxes. and reductants, (ii) closed SAFs that are fed with oxidative sintered chromite pellets, as well as lumpy reductants and fluxes, (iii) closed SAFs fed with prereduced chromite pellets, as well as lumpy reductants and fluxes, and (iv) closed direct current (DC) arc furnaces fed with fine (typically $\leq 6 \mathrm{~mm}$ ) chromite ore, fluxes, and reductants. Of particular interest for the present paper is the oxidative sintered pellet process, which is commercially known as the Outotec steel belt sintering process (Outotec, 2017).

Various authors have previously described the oxidative sintered pellet production process (Riekkola-Vanhanen, 1999; Beukes, Dawson, and van Zyl, 2010; Basson and Daavittila, 2013). Chromite fines (typically $\leq 1 \mathrm{~mm}$ ) are wet milled together with a small percentage of a carbonaceous material that serves as an energy source during sintering. The grain size specification that must be obtained during milling is typically a $d_{80}$ of $74 \mu \mathrm{m}(80 \%$ passing size of $74 \mu \mathrm{m}$ ). Ceramic filters are used to dewater the milled slurry to a moisture content of below $9 \%$. A fine clay binder (usually refined bentonite) is then mixed into the moist filter cake with a high-intensity mixer, and the moist mixture is pelletized in a pelletizing drum. The newly formed pellets are screened on a roller screen. Oversized pellets are broken down and recycled, together with undersized pellets. This leads to fairly homogeneously sized green (uncured) pellets with an average diameter of approximately $12 \mathrm{~mm}$. The green pellets are then layered on a

* Chemical Resource Beneficiation (CRB), NorthWest University, Potchefstroom, South Africa.

+ CanmetMINING, Natural Resources Canada, Ottawa, Canada.

(C) The Southern African Institute of Mining and Metallurgy, 2019. ISSN 2225-6253. Paper received Dec. 2017; revised paper received Aug. 2018. 


\section{Recycling pre-oxidized chromite fines in the oxidative sintered pellet production process}

perforated steel belt, which carries the pellets through a multi-compartment sintering furnace. The perforated steel belt is protected against excessive temperatures by a layer of previously sintered pellets below the green pellets. The temperature of the pellet bed gradually increases as it passes through the sintering furnace, reaching a maximum of approximately 1400 to $1500^{\circ} \mathrm{C}$. Sintered pellets are then cooled by air blown through the pellet bed from below. Thereafter, the sintered pellets are discharged and screened to remove $<6 \mathrm{~mm}$ material, but screening at a smaller aperture has also been observed by the authors during plant visits at $\mathrm{FeCr}$ producers applying this process. The overall process produces porous and mechanically strong pellets suitable for SAF smelting (Riekkola-Vanhanen, 1999), which results in improved SAF stability and metallurgical efficiency, as well as lower energy consumption compared with conventional SAF smelting of lumpy ore (Basson and Daavittila, 2013).

The suppliers of the steel belt sintering technology indicated that chromite-containing dusts collected from the pellet sintering scrubber and fines screened out from the sintered pellets can be re-introduced into the moist material mixture that is pelletized (Basson and Daavittila, 2013). However, it is specified that the addition must be limited to a maximum of $4 \mathrm{wt} \%$ of the total pellet composition, since this material is believed to adversely affect pellet quality (Basson and Daavittila, 2013). The fundamental reasoning behind this limitation is not stated in the public peer-reviewed domain. A recent personal communication indicated that specifically, pellet strength deteriorates with increasing content of recycled pre-oxidized fines (Päätalo, 2018). This can be countered by increasing the clay binder and carbon contents in the green pellets. However, an increased carbon content could lead to higher sintering temperatures, which may result in a shorter operational life of the steel sintering belt (Päätalo, 2018).

The authors were approached by a FeCr producer at which the generation of pre-oxidized fines, originating from the sintering scrubber and screening of the sintered pellets, exceeds the $4 \mathrm{wt} \%$ limitation. This has resulted in the accumulation of pre-oxidized fine chromite stockpiles. Preoxidized chromite requires less energy to metallize compared to normal chromite (Kapure et al., 2010). Furthermore, the reduction of oxidative sintered pellets requires less energy (Zhao and Hayes, 2010) and pre-oxidation of chromite fines significantly improves prereduction (solid-state reduction) of chromite (Kleynhans et al., 2016, 2017). Considering these energy-related benefits, the authors believe that all preoxidized fine chromite should be recycled on-site at $\mathrm{FeCr}$ producers. With this in mind, the possible recycling of preoxidized chromite fines into oxidative sintered pellets beyond the current limitation of $4 \mathrm{wt} \%$ pellet composition was investigated, considering both fundamental and practical aspects.

\section{Materials and methods}

\section{Materials}

A metallurgical grade chromite ore sample was received from a large FeCr producer in South Africa, which served as the case study ore in this investigation. To obtain a homogeneous, representative sample, a bulk sample of approximately $320 \mathrm{~kg}$ was taken by manually collecting shovel loads of material at various points and various heights of the ore stockpile. The bulk sample was then split at the laboratory of the FeCr producer three times with a riffle-type sample splitter to yield a sample of approximately $80 \mathrm{~kg}$, which was transported to the laboratories at the Chemical Resource Beneficiation (CRB) unit, North-West University. There, the sample mass required for a specific experiment was obtained by splitting the sample further using a vibrating feeder that fed a rotating tray of containers. Previously, Glastonbury et al., (2015) presented a detailed characterization of this case study ore, therefore such a characterization is not repeated here. In short, the ore contained $44.19 \mathrm{wt} \% \mathrm{Cr}_{2} \mathrm{O}_{3}, 24.68 \mathrm{wt} \% \mathrm{FeO}, 14.71 \mathrm{wt} \%$ $\mathrm{Al}_{2} \mathrm{O}_{3}$, wt\% $10.31 \mathrm{MgO}$, and $2.96 \mathrm{wt} \% \mathrm{SiO}_{2}$, and had a $\mathrm{Cr} / \mathrm{Fe}$ ratio of 1.58 (Glastonbury et al., 2015). This composition is representative of a typical South African metallurgical grade chromite ore (Cramer, Basson, and Nelson, 2004). It has to be considered that a substantial fraction of the chromite smelted outside South Africa originates from South Africa. In 2012 for instance, $28 \%$ of the chromite ore consumed in the rest of the world originated from South Africa (Kleynhans et al., 2016). Therefore, the results generated from the case study ore are of international relevance.

A sample of chromite fines screened out from industrially produced sintered pellets was obtained from a large $\mathrm{FeCr}$ producer in South Africa that utilizes the oxidative sintered pellet production process. In this paper, this material is referred to as 'pre-oxidized chromite'. This material was sampled in a similar manner as the ore. Refined bentonite (binder) and coke fines (carbon fuel source), which were used to produce oxidative sintered pellets at the aforementioned $\mathrm{FeCr}$ producer, were also obtained. Kleynhans et al., (2012, 2017) previously presented full characterizations of the bentonite and coke fines (sample Co5 in Kleynhans et al., 2017), therefore this information is not repeated here.

\section{Material preparation and pelletization}

Material for pelletization experiments was prepared by dry milling a $50 \mathrm{~g}$ mixture, consisting of $1.5 \mathrm{wt} \%$ coke, with chromite the balance, for 2 minutes in a Siebtechnik laboratory disc mill. Prior to milling, all materials were dried in an oven overnight at $75^{\circ} \mathrm{C}$ to enable accurate and repeatable batching of the mixtures. A tungsten carbide grinding chamber was used to avoid possible $\mathrm{Fe}$ contamination. This milling procedure yielded a particle size distribution with a $d_{80}$ of $75 \mu \mathrm{m}$, which is similar to the industrial particle size specification, i.e. $d_{80}$ of $74 \mu \mathrm{m}$ (Basson and Daavittila, 2013; Glastonbury et al., 2015). After milling, refined bentonite was added to obtain a mixture with a composition of $97.52 \mathrm{wt} \%$ ore, $1.49 \mathrm{wt} \%$ coke, and $0.99 \mathrm{wt} \%$ bentonite. The pelletization mixture was then vigorously blended for 15 minutes using a laboratory-scale Eirich-type mixer. As-received pre-oxidized chromite was then added to the pelletization mixture to obtain mixtures containing 4,8 , 16,32 , and 64 wt\% pre-oxidized chromite. No additional coke or bentonite was added to these mixtures to compensate for the addition of pre-oxidized chromite, since this is also the practice in industry. 


\section{Recycling pre-oxidized chromite fines in the oxidative sintered pellet production process}

Green pellets containing the various percentages of preoxidized chromite were generated using a laboratory-scale disk pelletizer. The laboratory disk pelletizer consisted of a $600 \mathrm{~mm}$ diameter flat steel disk with a $150 \mathrm{~mm}$ deep rim. The entire disk and rim were pressed from a single steel plate and the connection area between the disk and rim was rounded to limit material build-up. The pelletizer rotated at a speed of $40 \mathrm{r} / \mathrm{min}$ and a constant angle of $60^{\circ}$ to the horizontal was maintained in all experiments. Fine water spray was introduced to the mixture with a handheld spray bottle to initiate pellet nucleation, i.e. formation of micro-pellets. Thereafter, the micro-pellets were grown by continuously wetting of their surfaces with water spray and introducing new, dry feed until the desired pellet diameter was achieved. Material build-ups on the bottom, side, and pelletizer corner (connecting area between disk and rim) were continuously loosened with a fit-for-purpose handheld scraper to facilitate the inclusion of this material into the pellets. This scraper had a flat edge to remove material build-up from the disk and the rim, as well as a rounded point to remove material buildup from the corner. Pellets with a diameter of $>11$ and $<13 \mathrm{~mm}$ were collected by screening. Care was taken to ensure a consistent pellet moisture content, with all pellets used in further experiments containing $5.5 \pm 0.7 \mathrm{wt} \%$ moisture. Pellet moisture contents were determined with an ADAM PMB 53 moisture balance. Green pellets were allowed to dry in an ambient atmosphere after collection before oxidative sintering experiments proceeded.

\section{Pellet oxidative sintering}

As previously stated, Basson and Daavittila (2013) indicated that industrially produced oxidative sintered pellets are heated to maximum temperatures of between 1400 and $1500^{\circ} \mathrm{C}$. Glastonbury et al., (2015) mimicked the industrially applied process on the laboratory scale, with a temperature profile that attained a maximum temperature of $1400^{\circ} \mathrm{C}$. However, these authors did not verify how deep into the pellets oxidation proceeded. Zhao and Hayes (2010) proved that only the outer chromite grains of industrially produced oxidative sintered pellets are partially oxidized, while the chromite grains deeper into the pellets are not oxidized. Heat transfer to pellets in laboratory conditions, where small amounts of pellets are sintered in batches with very effective furnaces, will be significantly superior to that in industrial furnaces, where very large quantities are treated continuously. Therefore, rather than blindly selecting a maximum sintering temperature, or applying the temperature profile used by Glastonbury et al., (2015), the authors tested various maximum temperatures. A Lenton Elite camber furnace (UK, Model BRF 15/5) with a programmable temperature controller was used for sintering. The temperature probe of this furnace was situated inside the heating chamber, which ensured that the recorded temperature and the actual pellet temperatures correlated well. Prior to oxidative sintering, the pellets (in a 99.7\% $\mathrm{Al}_{2} \mathrm{O}_{3}$ ceramic crucible) and furnace were pre-heated to 100 and $900^{\circ} \mathrm{C}$, respectively. A pellet batch (consisting of 25 pellets) was then placed in the furnace and the temperature was ramped up from $900^{\circ} \mathrm{C}$ to the designated maximum temperature at a rate of approximately $17^{\circ} \mathrm{C} / \mathrm{min}$. Once the designated maximum temperature was reached, the pellets were removed from the furnace and allowed to cool in the ambient atmosphere. The sintering process also took place in an ambient gaseous environment and no dwelling time was allowed at the maximum temperature, in order to mimic the industrial process as closely as possible.

\section{Analytical techniques}

Scanning electron microscopy (SEM) equipped with energy dispersive X-ray spectroscopy (EDS) was used to perform surface characterization of the sintered pellets in secondary electron mode. An FEI Quanta 250 FEG instrument incorporating an Oxford X-map EDS system operating at $15 \mathrm{kV}$ and a working distance of $10 \mathrm{~mm}$ was used. Pellets were split in half and mounted on aluminium stubs, or were set in resin and polished with a SS20 Spectrum System Grinder polisher before being mounted on the stubs. The polished resin-embedded samples were coated with carbon in an Emscope TB 500 carbon coater prior to SEM analysis. Resin-embedded polished pellets were imaged in backscattered electron mode, and un-embedded pellets in secondary electron mode.

Crystalline phase analysis of bulk samples was performed by X-ray diffraction (XRD) using two methods:

> A Rigaku D/MAX 2500 rotating-anode powder diffractometer with $\mathrm{Cu} \mathrm{K} \alpha$ radiation at $50 \mathrm{kV}, 260 \mathrm{~mA}$, a step-scan of $0.02^{\circ}$, and a scan rate at $1 / \mathrm{min}$ in 2 hours from 5 to $70^{\circ}$. Phase identification was performed using JADE v.3.9 with the ICDD and ICSD diffraction databases

> A Röntgen diffraction system (PW3040/60 X'Pert Pro) and a back-loading preparation method to determine the crystalline phases, and their percentages, present in size-partitioned samples and milled mixtures.

The samples were scanned using X-rays generated by a copper ( $\mathrm{Cu}) \mathrm{K} \alpha \mathrm{X}$-ray tube. Measurements were carried out between variable divergence and fixed receiving slits. Phases were identified using X'PertHighscore plus software. Phase refinement was performed using the Rietveld method (Hill and Howard, 1987).

Further analysis was undertaken by mounting crosssectioned polished pellets on glass slides and carbon-coating them prior to electron microprobe analysis (EMPA). Analysis was performed using a JEOL JXA-8900 electron microprobe fitted with five wavelength-dispersive spectrometers at an accelerating voltage of $20 \mathrm{kV}$ and beam current of $26 \mathrm{nA}$.

\section{Pellet compressive strength and abrasion resistance}

The compressive strengths of sintered pellets were determined using an Ametek Lloyd Instruments LRXplus $5 \mathrm{kN}$ strength tester. NEXYGENPlus material test and data analysis software was used to capture and process the generated data, as well as to control and monitor all aspects of the system. The speed of the compression plates was kept to $10 \mathrm{~mm} / \mathrm{min}$ during compressive strength tests in order to apply an increasing force on the prepared pellets. The maximum load to induce pellet breakage was recorded. Standard deviations were calculated based on 10 experimental repetitions.

The abrasion resistance apparatus used in this study was based on a downscaled version of the European Standard EN 15051 rotating drum, as described by Schneider and Jensen (2008). The same drum was utilized in previous studies 


\section{Recycling pre-oxidized chromite fines in the oxidative sintered pellet production process}

(Kleynhans et al., 2012, 2016; Neizel et al., 2013; Glastonbury et al., 2015). During each experiment, 10 sintered pellets were abraded at $40 \mathrm{r} / \mathrm{min}$ rotational speed for 64 minutes. The pellets were screened at time intervals of. 1 , $2,4,8,16,32$, and 64 minutes using a sieve with an aperture of $6.5 \mathrm{~mm}$. This aperture was chosen since $<6 \mathrm{~mm}$ material is generally classified as fines, which have to be limited in SAF feed material (Basson and Daavittila, 2013). The oversized materials $(\geq 6.5 \mathrm{~mm}$ ) were weighed and returned to the drum, together with the fines $(\leq 6.5 \mathrm{~mm})$, for further abrasion until the full abrasion time, i.e. 64 minutes, was reached. Standard deviations were calculated based on three experimental repetitions.

\section{Results and discussion}

\section{Mimicking the industrial applied oxidative sintering process}

As previously stated, Zhao and Hayes (2010) showed that only the outer chromite grains of industrially produced oxidative sintered pellets are partially oxidized, while the grains deeper into the pellet cores remain unoxidized. Therefore, it was critical to establish the maximum temperature for the proposed laboratory sintering profile (see Pellet oxidative sintering section). Consequently, batches of pellets were cured with sintering profiles that had maximum temperatures from 1000 to $1500^{\circ} \mathrm{C}$. SEM examination of three cross-sectioned, polished sintered pellets, which were randomly selected from each prepared pellet batch, revealed that the outer chromite grains of pellets sintered at $<1200^{\circ} \mathrm{C}$ did not indicate signs of oxidation, while oxidation penetrated deep into pellets sintered at $>1200^{\circ} \mathrm{C}$. A sintering profile with a maximum temperature of $1200^{\circ} \mathrm{C}$ was therefore applied within the context of this paper, to mimic the industrially applied oxidative sintered pellets process. Figure 1 presents backscattered electron SEM micrographs of a cross-sectioned polished pellet containing zero $\mathrm{wt} \%$ pre-oxidized chromite, which was sintered at a maximum temperature of $1200^{\circ} \mathrm{C}$. Oxidation-induced differences (alteration being indicated by the lighter greyscale patterns) were evident between the outer chromite grains and grains toward the centre of the pellet (Figure 1a). The higher magnification micrograph of the outer chromite grains (Figure 1b) clearly shows an oxidation-induced altered phase that formed on the rim of such grains, while the chromite grains toward the pellet centre were unaffected (Figure 1c). Similar oxidation-induced phase patterns have been observed during investigations considering pre-oxidation of chromite prior to direct reduction (Kapure et al., 2010), laboratory oxidative sintering of chromite pellets (Glastonbury et al., 2015), and industrially produced oxidative sintered chromite pellets (Zhao and Hayes, 2010).

\section{Mechanism of chromite oxidation}

In order to gain insight into the recycling of pre-oxidized chromite fines, it is vital to understand the mechanism(s) at

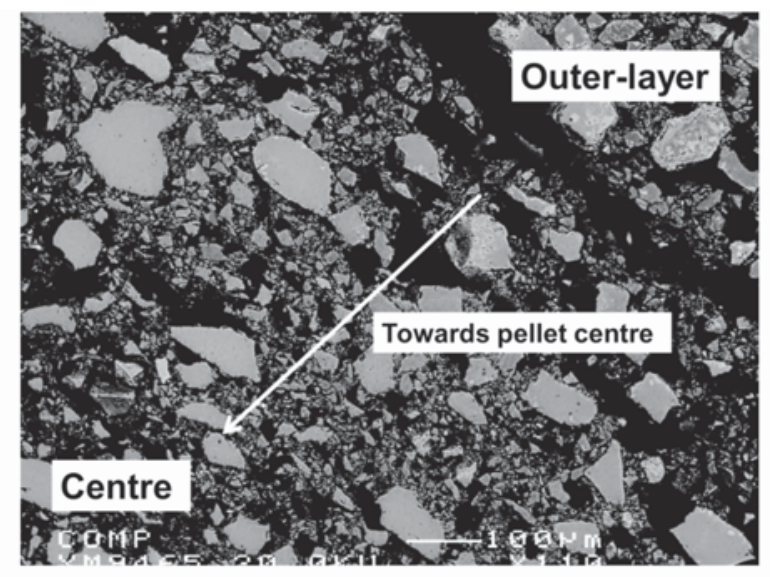

(a)

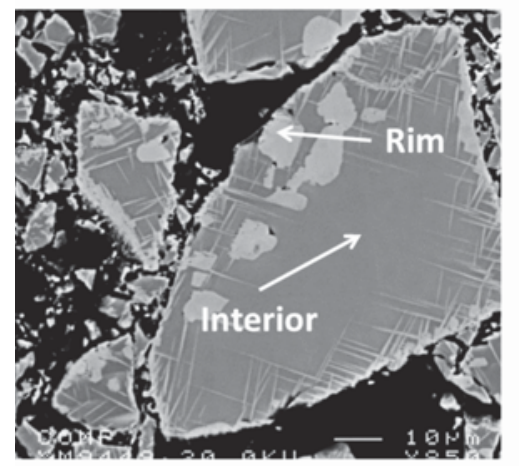

(b)

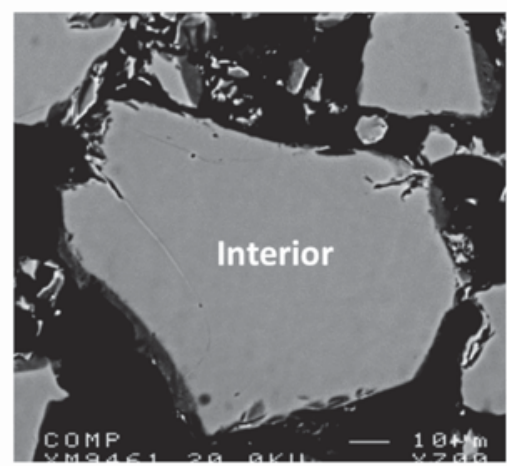

(c)

Figure 1-Backscattered electron SEM micrographs of a cross-sectioned and polished pellet containing zero wt\% pre-oxidized chromite sintered at a maximum temperature of $1200^{\circ} \mathrm{C}$. Oxidation-induced differences (indicated by the lighter greyscale patterns) are evident between the outer chromite grains and grains toward the centre (a). These differences are better seen in the higher magnification images of the outer chromite grains (b) and grains toward the centre of the pellet (c) 


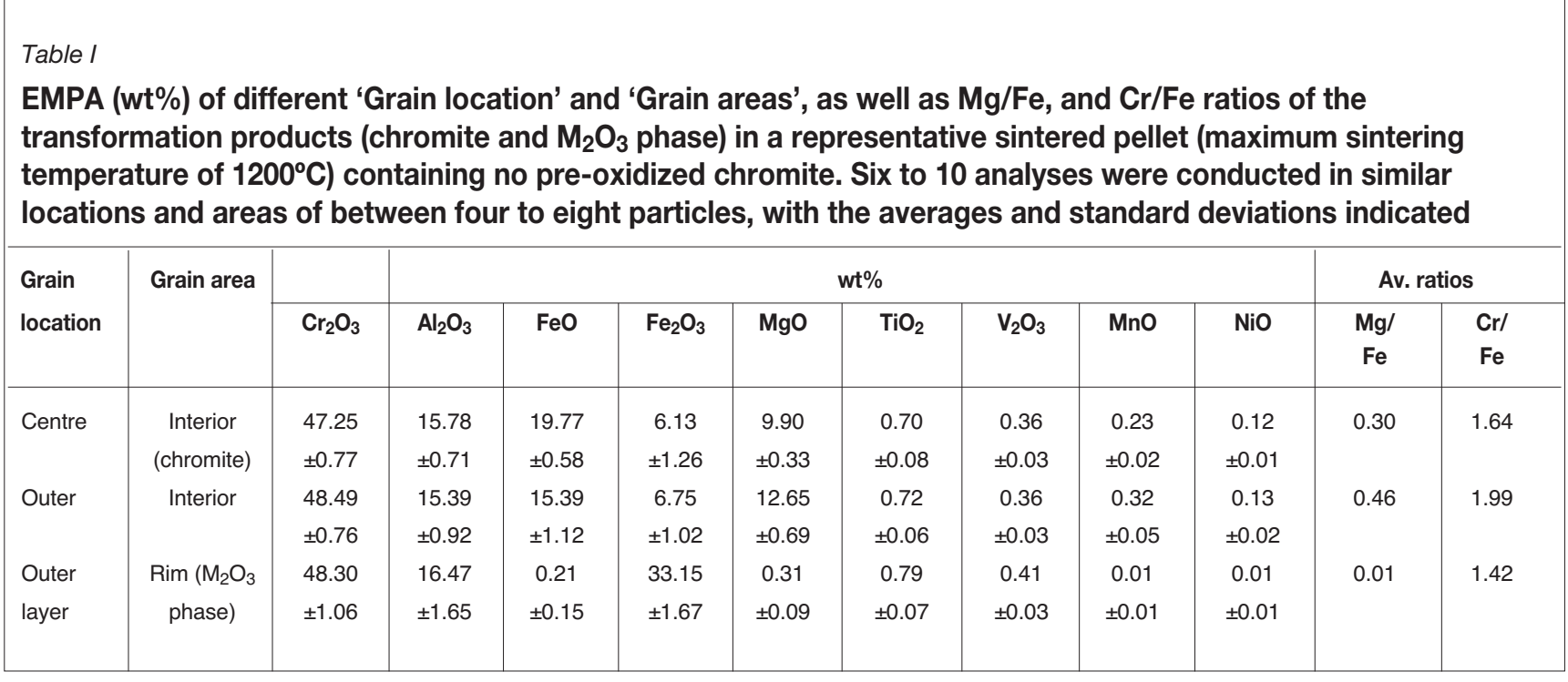

play during the oxidative sintered pellet production process. Oxidation-induced alteration, which is indicated by lighter greyscale patterns in the SEM micrographs in Figure 1b, was evident on the rims of the outer chromite grains of sintered pellets containing no pre-oxidized chromite. EMPA was subsequently used to determine the chemical compositions of the transformation products. However, access to the EMPA was limited, therefore only one pellet, sintered according to the optimum sintering profile, was analysed. SEM micrographs of all three of the randomly selected pellets from the batch sintered at $1200^{\circ} \mathrm{C}$ indicated the same phase transformations at the rim of the pellets (see Mimicking the industrial applied oxidative sintering process section), which proved that the randomly selected pellet analysed with EMPA was representative. The results of the EMPA are shown in Table I. The areas analysed are indicated as 'grain location' and 'grain area', with 'location' referring to the position of the chromite grain within the pellet (i.e. centre or outer grains), and 'grain area' referring to the zone within a specific grain (i.e. interior or rim of a specific grain, which is also indicated in Figure $1 \mathrm{~b}$ ). The $\mathrm{Cr} / \mathrm{Fe}$ and $\mathrm{Mg} / \mathrm{Fe}$ elemental ratios, with $\mathrm{Fe}=\mathrm{Fe}^{2+}+\mathrm{Fe}^{3+}$, as determined by EMPA, are also presented in Table I.

As is evident from Table I, the interiors of grains at the centre and outer layer of the pellets had appreciably different $\mathrm{MgO}$ and $\mathrm{FeO}$ contents, whereas no appreciable differences between trivalent cations (primarily $\mathrm{Cr}^{3+}, \mathrm{Al}^{3+}$, and $\mathrm{Fe}^{3+}$, indicated as $\mathrm{Cr}_{2} \mathrm{O}_{3}, \mathrm{Al}_{2} \mathrm{O}_{3}$, and $\mathrm{Fe}_{2} \mathrm{O}_{3}$, respectively) occupying the octahedral sites in chromite were observed. In contrast, relatively large differences in $\mathrm{FeO}, \mathrm{Fe}_{2} \mathrm{O}_{3}$, and $\mathrm{MgO}$ contents were evident for grain interiors and rims located in the outer layer of pellets.

Grain interiors in the centre of pellets had an $\mathrm{MgO}$ content of $9.90 \mathrm{wt} \%$, compared to $12.65 \mathrm{wt} \%$ at the outer layer. The $\mathrm{FeO}$ content of grain interiors at the centre and outer layer of pellets were 19.77 and $15.93 \mathrm{wt} \%$, respectively. Consequently, the $\mathrm{Mg} / \mathrm{Fe}$ ratios for grain interiors at the pellet outer layer were higher $(0.46)$ than for grains at the pellet centre (0.30). The $\mathrm{Mg} / \mathrm{Fe}$ ratio difference of grain interiors as a function of location within the pellet was indicative of $\mathrm{Mg}^{2+}$ enrichment at the expense of $\mathrm{Fe}^{2+}$ in grains at the outer layer. $\mathrm{Fe}^{2+}$ occupies the tetrahedral sites in normal (untreated) chromite spinel. High-temperature oxidative treatment of chromite caused $\mathrm{Fe}^{2}+$ to oxidize and diffuse towards the grain rim, generating tetrahedral site vacancies within the particle interior. Vacancy formation occurs according to the following reaction (Lindsley, 1991; Tathavakar, Antony, and Jha., 2005)

$$
0.5 \mathrm{O}_{2} \stackrel{T}{\rightarrow} \mathrm{O}^{2-}{ }_{0}+\mathrm{V}_{\text {cat }}+2 h
$$

where $\mathrm{O}^{2-}{ }_{0}$ represents oxygen anions in the cubic closed packed lattice, $\mathrm{V}_{\text {cat }}$ is the cation vacancies, and $h$ a 'hole', respectively. $\mathrm{V}_{\text {cat }}+2 h$ collectively represent mobile point defects, from which mass transfer occurs. These tetrahedral vacancies were filled by $\mathrm{Mg} 2+$ (originating from the particle rim) via a $\mathrm{Mg}$-Fe exchange reaction, which resulted in the observed $0.31 \mathrm{wt} \% \mathrm{MgO}$ content at the grain rim in the pellet outer layer.

The $\mathrm{Fe}^{2+}$ that migrated to the grain rim in the pellet outer layer was subsequently oxidized to $\mathrm{Fe}^{3+}$, or alternatively the $\mathrm{Fe}^{2+}$ was oxidized to $\mathrm{Fe}^{3}+$ which then migrated to the surface - currently it is impossible to say with certainty which occurs first. The generalized oxidative spinel phase decomposition is described by Equation [2] (Alper, 1970; Tathavakar, Antony, and Jha, 2005)

$$
(\mathrm{A})[\mathrm{B}]_{2} \mathrm{O}_{4} \rightarrow(\mathrm{AO})+\left[\mathrm{B}_{2} \mathrm{O}_{3}\right]
$$

The products of complete oxidative decomposition of chromite $(\mathrm{Mg}, \mathrm{Fe})[\mathrm{Al}, \mathrm{Cr}, \mathrm{Fe}]_{2} \mathrm{O}_{4}$ at elevated temperatures are free oxides of the various species, as indicated by Equation [2]. However, in this study complete oxidative decomposition was not the intention, nor was it achieved. The products of chromite oxidation are strongly dependent on temperature, oxygen partial pressure, and the chemical composition of the chromite. In the presence of oxygen, $\mathrm{Fe}^{2+}$ will be oxidized to $\mathrm{Fe}^{3+}$ at sufficiently high temperatures. This explains the decrease in $\mathrm{FeO}$ content of $15.39 \%$ to $0.21 \%$ and increase in $\mathrm{Fe}_{2} \mathrm{O}_{3}$ content of 6.75 to $33.15 \%$ from the grain interior to 


\section{Recycling pre-oxidized chromite fines in the oxidative sintered pellet production process}

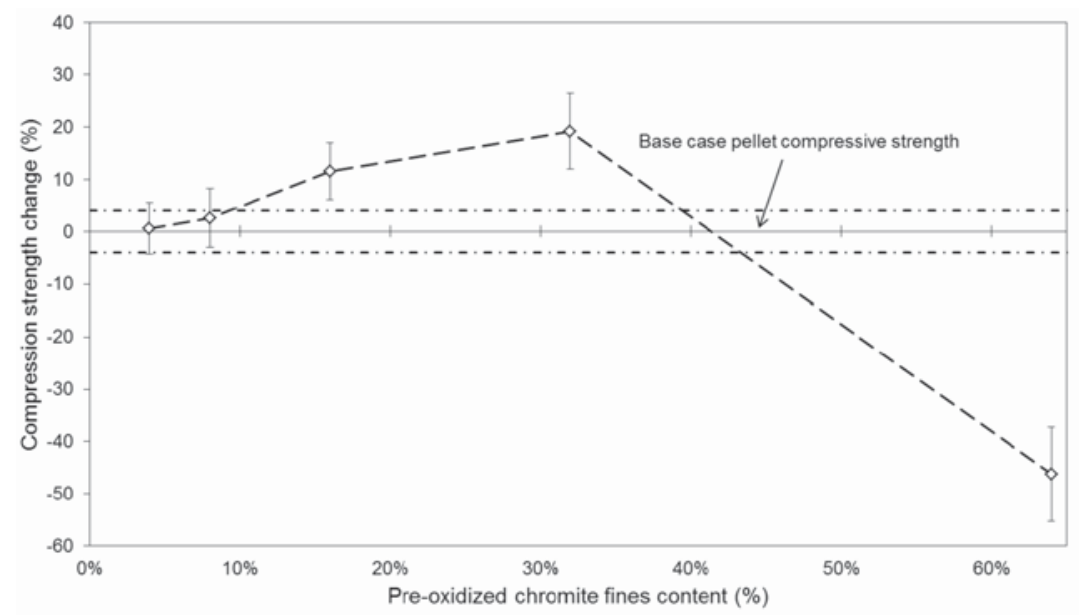

Figure 2-The effect of pre-oxidized chromite fines content on cured pellet compressive strength. The error bars indicate the standard deviations of 10 experimental repeats

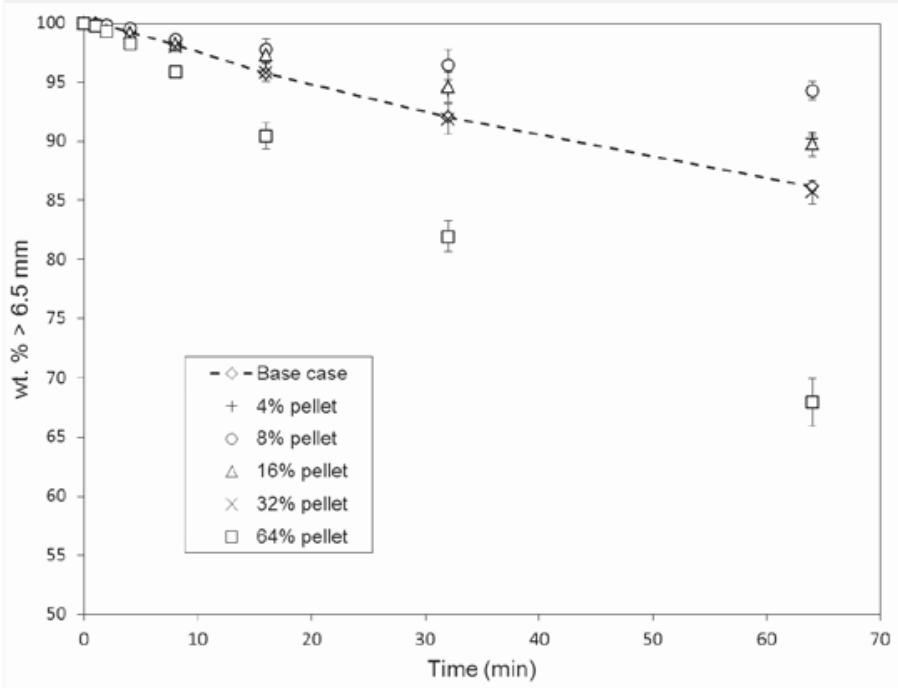

Figure 3-The effect of pre-oxidized chromite fines content on cured pellet abrasion strength. The error bars indicate the standard deviations of three experimental repeats

the rim of the pellet outer layer. Ultimately, this results in the exsolution of a $\mathrm{Fe}_{2} \mathrm{O}_{3}$-rich sesquioxide phase along the chromite grain rims and cleavage planes, as shown in Figure $1 \mathrm{~b}$ and identified in Table I. Such Widmänstatten intergrowths of sesquioxide phase $\left(\mathrm{M}_{2} \mathrm{O}_{3}\right.$, with $\mathrm{M}$ representing a series of trivalent ions such as $\mathrm{Cr}^{3+}, \mathrm{Al} 3+$, and $\mathrm{Fe}^{3+}$ ) during chromite oxidation, have been identified by various authors (Tathavakar, Antony, and Jha, 2005; Kapure et al., 2010; Zhao and Hayes, 2010; Glastonbury et al., 2015). It is believed that the sesquioxide $\mathrm{Fe}_{2} \mathrm{O}_{3}$ phase is initially present as metastable, intermediate maghemite $\left(\gamma-\mathrm{Fe}_{2} \mathrm{O}_{3}\right)$ exsolved precipitate, which forms by changing an $\mathrm{ABC}$ packing into an $\mathrm{ABAB}$ packing by dislocations along the (111) chromite spinel plane. The maghemite phase then decomposes to the more stable hematite $\left(\mathrm{Fe}_{2} \mathrm{O}_{3}\right)$ phase at elevated temperatures $\left(>600^{\circ} \mathrm{C}\right)$ in the presence of oxygen $\left(P_{\mathrm{O}_{2}}=0.2 \mathrm{~atm}\right.$.) (Tathavakar et al., 2005; Pan, Yang, and $\mathrm{Zhu}, 2015)$. The presence of Al3+ cations increases the oxidative decomposition temperature as they can occupy vacancies present in the maghaemite structure (Hellwege and Hellwege, 1970).

Furthermore, chromite oxidation resulted in variations in the $\mathrm{Cr} / \mathrm{Fe}$ ratio at the grain interiors and rims as a function of grain location within the pellet. The unoxidized chromite had a $\mathrm{Cr} / \mathrm{Fe}$ ratio of 1.64 , which correlated well with typical $\mathrm{Cr} / \mathrm{Fe}$ ratios of South African chromite ore originating from the Middle Group 1 and 2 seams of the Bushveld Complex (Basson, Curr, and Gericke, 2007; Kleynhans, 2011). Chromite near the grain rim in the outer layer of sintered pellets had a $\mathrm{Cr} / \mathrm{Fe}$ ratio of 1.42 as opposed to 1.99 near the grain interior, which resulted from Fe diffusion from the grain interior towards the grain rim.

\section{$X R D$ characterization of pre-oxidized chromite fines}

Quantitative Rietveld refined XRD analysis was performed on the as-received pre-oxidized chromite fines. The phases found (in order of decreasing abundance) were chromite $39.9 \mathrm{wt} \%$, chromian spinel $42.9 \mathrm{wt} \%$, haematite $5.1 \mathrm{wt} \%$, 


\section{Recycling pre-oxidized chromite fines in the oxidative sintered pellet production process}

and enstatite $12.0 \mathrm{wt} \%$. The chromite phase represents residual chromite. The chromian spinel chromite formed at $1200^{\circ} \mathrm{C}$ in the presence of oxygen. Tathavakar et al., (2015) stated that South African chromite decomposes into two spinel phases upon heating, i.e. $\left(\mathrm{Mg}_{1-\mathrm{x}}, \mathrm{Fe}_{\mathrm{x}}\right)\left(\mathrm{Cr}_{1-\mathrm{y}}, \mathrm{Al}_{\mathrm{y}}\right)_{2} \mathrm{O}_{4}$ and $\left(\mathrm{Fe}_{1-\mathrm{a}}, \mathrm{Mg}_{\mathrm{a}}\right)\left(\mathrm{Cr}_{1-\mathrm{b}}, \mathrm{Al}_{\mathrm{b}}\right)_{2} \mathrm{O}_{4}$. The two observed chromite phases, i.e. chromite and chromian spinel, were in agreement with phases detected by Tathavakar, Antony, and Jha (2015). Furthermore, the detection of hematite $\left(\mathrm{Fe}_{2} \mathrm{O}_{3}\right)$ indicated that free $\mathrm{Fe}_{2} \mathrm{O}_{3}$, which formed as described in the section Mechanism of chromite oxidation, was present in the pre-oxidized chromite fines. The enstatite phase likely originated from siliceous gangue minerals, clay that was added as a pellet binder, and ash from the coke (in-pellet carbon fuel source).

\section{Pellet compressive and abrasion resistance strengths}

If pre-oxidized chromite fines were to be recycled into oxidative sintered pellets beyond the current limitation of $4 \mathrm{wt} \%$ (Basson and Daavittila, 2013), such pellets must be physically strong enough to prevent fines formation. Figures 2 and 3 present the cured compressive and abrasion resistance strengths of pellets containing $4,8,16,32$, and $64 \mathrm{wt} \%$ pre-oxidized chromite fines, compared to pellets containing zero wt\% pre-oxidized chromite fines (indicated by the $y$-axis).

From Figures 2 and 3, it is evident that pellet compressive and abrasion resistance strengths remained the same, or improved, compared to the base case (zero wt\% preoxidized chromite fines) as the pre-oxidized chromite fines content increased from 4 to $32 \mathrm{wt} \%$. However, pellets containing $64 \mathrm{wt} \%$ pre-oxidized chromite fines were substantially weaker. It thus seems feasible to include up to $32 \mathrm{wt} \%$ pre-oxidized chromite fines in oxidative sintered pellet mixtures without adversely affecting cured pellet strengths. However, it is unlikely that such large additions would ever be required.

There might be various reasons why the cured sintered pellets containing pre-oxidized chromite fines (at least up to $32 \mathrm{wt} \%$ containing pellets) were stronger than the base case. However, the most obvious is that the cured sintered pellets containing pre-oxidized chromite fines contained a larger proportion of ultrafine particles, as is evident from a comparison of Figures $4 \mathrm{a}$ and $4 \mathrm{~b}$. These ultrafine particles filled interparticle gaps and improved particle contact, which enhanced cured pellet strength. The presence of the ultrafine particles in the pre-oxidized chromite fines can be related to the phase/chemical nature thereof. EMPA indicated that sesquioxide $\mathrm{Fe}_{2} \mathrm{O}_{3}$ phases were formed in outer layer pellet chromite grains (see Mechanism of chromite oxidation section, Table I) during pellet oxidative sintering. Quantitative Rietveld refined XRD analysis even indicated the presence of haematite (XRD characterization of pre-oxidized chromite fines section) in the pre-oxidized chromite fines. Zhao and Hayes (2010), who also investigated oxidative sintered chromite pellets, found that the phase transformation responsible for $\mathrm{Fe}_{2} \mathrm{O}_{3}$ formation resulted in a shear mechanism (i.e. crystal stress/strain build-up) that can cause crystalline mechanical break-up, thereby generating the ultrafine particles observed in the pre-oxidized chromite fines (Figure $4 b$ ).

In addition to the particle size-related enhancement of cured pellet strength, particle surface morphology was also considered. Surface SEM micrographs of pellets containing zero and $16 \mathrm{wt} \%$ pre-oxidized chromite fines pellets are presented in Figures $5 a$ and $5 b$, respectively. The most notable difference in surface morphology is the enhanced interparticle sintering of the cured sintered pellets containing pre-oxidized chromite fines. This suggests that some additional degree of melting occurred during sintering, probably due to the presence of pre-oxidized chromite fines. Obviously, this can at least in part be attributed to the better interparticle contact and reduced interparticle voids, but it was also important to investigate the chemical nature of the interparticle bonding. SEM-EDS analyses of the areas highlighted with the white blocks in Figures $5 \mathrm{a}$ and $5 \mathrm{~b}$ indicated similar chemical compositions. This suggests that the siliceous gangue minerals, clay as the pellet binder, and ash from the coke (in-pellet carbon fuel source) jointly contributed to binding the particles together via the formation of a molten phase. Figure 6a present a SEM micrograph of a typical pre-oxidized chromite fines particle,

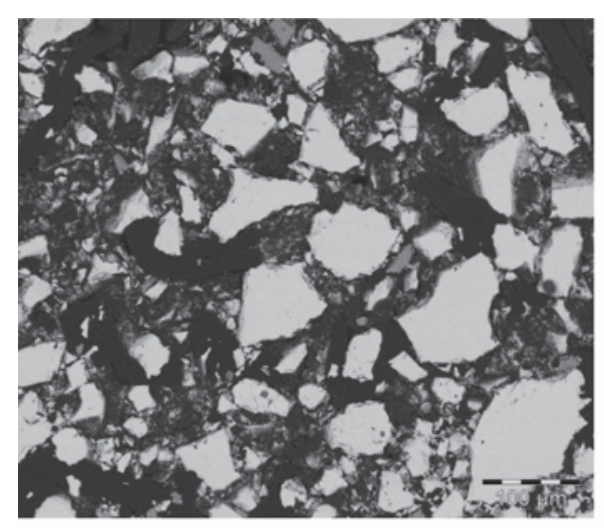

(a)

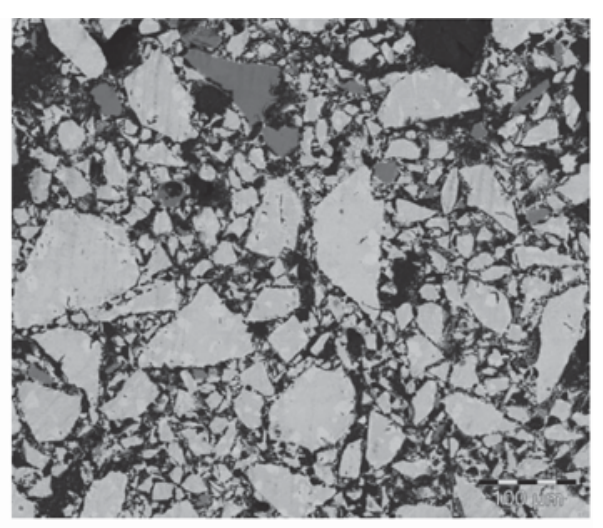

(b)

Figure 4-Backscattered electron SEM micrographs of a cross-sectioned cured pellet containing (a) zero wt $\%$ and (b) 32 wt $\%$ pre-oxidized chromite fines 


\section{Recycling pre-oxidized chromite fines in the oxidative sintered pellet production process}

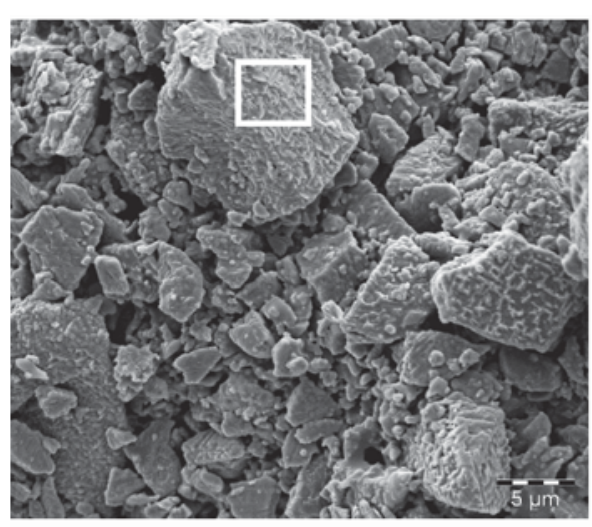

(a)

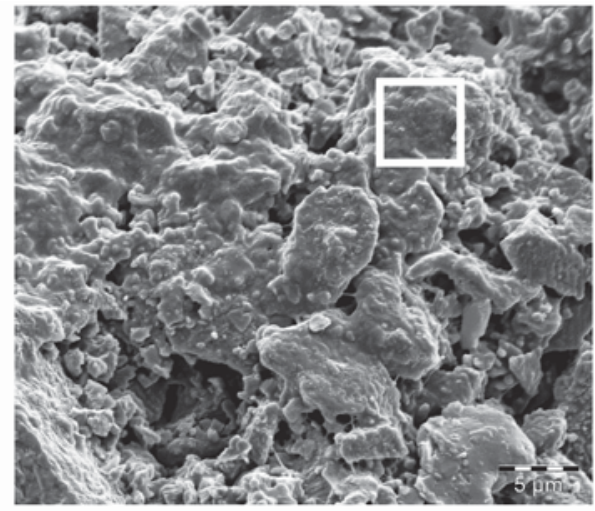

(b)

Figure 5-Secondary electron SEM micrographs of the particle morphologies with surface features of pellets containing (a) zero and (b) 16 wt $\%$ pre-oxidized chromite fines containing pellets. The white boxes indicate areas analysed by SEM-EDS

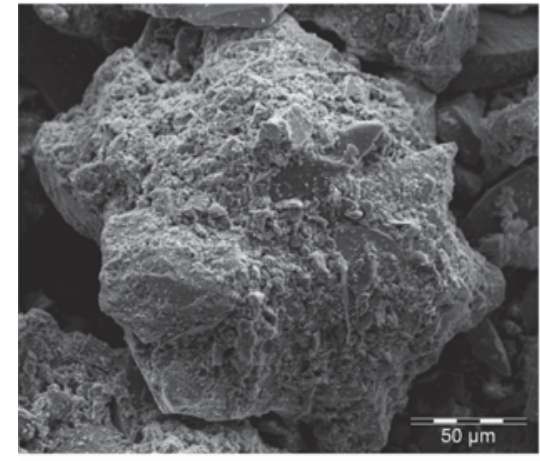

(a)

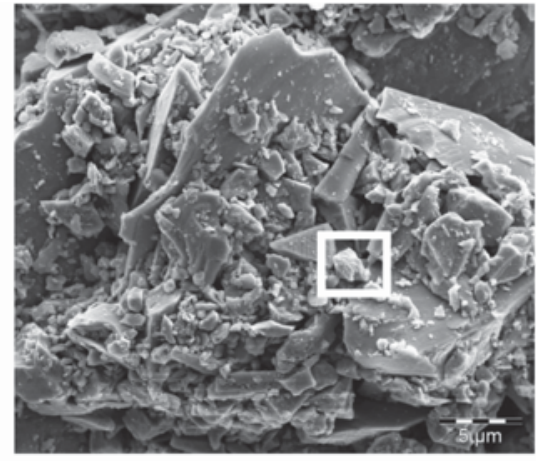

(b)

Figure 6-Secondary electron SEM micrographs of a typical pre-oxidized chromite fines particle at two magnifications. The white box highlights an aluminosilicate-type particle that enables interparticle binding due to the formation of a molten phase

while the white box in Figure $6 \mathrm{~b}$ indicate the presence of a aluminosilicate type particle (SEM-EDS composition of $4.0 \mathrm{wt} \% \mathrm{Al}, 8.0 \mathrm{wt} \% \mathrm{Si}, 7.7 \mathrm{wt} \% \mathrm{Mg}$, and $0.5 \mathrm{wt} \% \mathrm{Ca}$ ). Considering that the interparticle bridges in the samples with and without the pre-oxidized chromite fines were compositionally similar, the difference in their sintered compressive and abrasion strengths can most likely be attributed to the presence of more ultrafine particles in the pre-oxidized chromite fines.

\section{Conclusions}

The findings presented in this paper suggest that preoxidized chromite fines, originating from the oxidative pellet sintering scrubber, and fines screened out from oxidative sintered pellets may be re-introduced into the moist material mixture that is pelletized in excess of the current $4 \mathrm{wt} \%$ limit indicated by the technology supplier. EMPA and quantitative XRD analysis verified the formation of $\mathrm{Fe}_{2} \mathrm{O}_{3}$-rich sesquioxide phases and/or liberated $\mathrm{Fe}_{2} \mathrm{O}_{3}$. Such phases will metallize at lower temperatures during smelting compared to normal chromite; hence possibly enhancing metallurgical efficiency and reducing electricity consumption. The authors therefore recommend that pre-oxidized chromite fines can be recycled in excess of the current $4 \mathrm{wt} \%$ limitation, but only after considering the following aspects.

> An appropriate techno-economic study should be conducted to assess the financial viability of the changes to the process.

> Practical implications, such as equipment modifications, as well as equipment and/or process licensing/warranty issues. For instance, the crushing of oversized green pellets and the operational lifetime of the steel sintering belt were not considered in this paper. Currently, oversized green pellets are crushed with a roller before the moist material is recycled to the pelletizing drum. This roller might be damaged by larger hard particles in the pre-oxidized chromite fines if this material is mixed with the moist material that is pelletized. This can be avoided by replacing the roller by a more robust crushing device, or alternatively milling the pre-oxidized chromite fines with the ore and carbonaceous material to prevent roller damage. As previously mentioned, increased recycling of preoxidized chromite fines might also require higher 


\section{Recycling pre-oxidized chromite fines in the oxidative sintered pellet production process}

carbon additions in the green pellets, which could be shorten the operational lifetime of the steel sintering belt. However, our results indicate that increased recycling of pre-oxidized chromite fines up to a very high percentage does not adversely influence sintered pellet strength. Such decisions (how to introduce larger, hard pre-oxidized particles and the effect of increased recycling of pre-oxidized fines on the steel sintering belt) will be guided by the techno-economic study of the process alteration options, and additionally by equipment and/or process licensing/warranty issues. However, the possible metallurgical and energy benefits associated with recycling of pre-oxidized chromite fines, which have up to now largely been ignored, should also be considered.

\section{Acknowledgements}

The authors thank Sarel Naude from the Department of Mechanical Engineering for assistance during sample preparation. Thanks are also given to Derek Smith and Dominique Duguay at CANMET for XRD and electron microprobe analyses, respectively. The financial assistance of the National Research Foundation (NRF) towards the PhD study of S.P. du Preez (grant number 101345) is hereby acknowledged. Opinions expressed and conclusions arrived at, are those of the authors and are not necessarily to be attributed to the NRF.

\section{References}

AlPER, A.M. 1970. High Temperature Oxides, Academic Press, New York

BASSON, J., CURR, T., and GERICKE, W. 2007. South Africa's ferroalloys industry present status and future outlook. Proceedings of the 11th International Ferroalloys Congress (INFACON XI). Das, R.K. and Sundaresan, T.S. (eds). Indian Ferro Alloys Producers Association, New Delhi. pp. 3-24.

BASSON, J., and DAAVITTILA, J. 2013. High carbon ferrochrome technology. Handbook of Ferroalloys: Theory and Technology. Gasik, M. (ed.) Elsevier Science, UK. Chapter 9. pp. 317-363. http://dx.doi.org/10.1016/B978-0-08-097753-9.00009-5

Beukes, J.P., DAwson, N.F., and van ZyL, P.G. 2010. Theoretical and practical aspects of $\mathrm{Cr}(\mathrm{VI})$ in the South African ferrochrome industry. Journal of the Southern African Institute of Mining and Metallurgy, vol. 110, no. 12. pp. 743-750.

Beukes, J.P., du Preez, S.P., van Zyl, P.G., Paktunc, D., Fabritius, T., PäÄtalo, M., and Cramer, M. 2017. Review of $\mathrm{Cr}$ (VI) environmental practices in the chromite mining and smelting industry-relevance to development of the Ring of Fire, Canada. Journal of Cleaner Production, vol. 165. pp. 874889. https://doi.org/10.1016/j.jclepro.2017.07.176

Cramer, L.A., Basson, J., and Nelson, L.R. 2004. The impact of platinum production from UG2 ore on ferrochrome production in South Africa. Journal of the South African Institute of Mining and Metallurgy, vol. 104, no. 9. pp 517-527.

Glastonbury, R.I., BeuKes, J.P, van ZyL, P.G, SAdiKI, L.N, JoRdAan, A., CAMPBeLL, Q.P, StEWART, H.M, and Dawson, N.F. 2015. Comparison of physical properties of oxidative sintered pellets produced with UG2 or metallurgical-grade South African chromite: A case study. Journal of the Southern African Institute of Mining and Metallurgy, vol. 115, no. 8. pp. 699-706. http://dx.doi.org/10.17159/2411-9717/2015/V115N8A6

HAGGERTY, S.E. 1991. Oxide mineralogy of the upper mantle. Reviews in Mineralogy and Geochemistry, vol. 25, no. 1. pp. 355-416.

Hellwege, K.H., and HellwEGE, A.H. 1970. Landolt-Bornsten Numerical Data and Functional Relation in Science and Technology. Springer-Verlag. b52, a18-a20.
HILL, R., and HowARD, C. 1987. Quantitative phase analysis from neutron powder diffraction data using the Rietveld method. Journal of Applied Crystallography, vol. 20, no. 6. pp. 467-474.

https://doi.org/10.1107/S0021889887086199

ICDA. 2013. Statistical Bulletin 2013 Edition. International Chromium Development Association, Paris, France.

Kapure, G., TathavadKar, V., Rao, C.B., Rao, S.M., and Raju, K.S. 2010. Coal based direct reduction of preoxidized chromite ore at high temperature. Proceedings of the 12th International Ferroalloys Congress (INFACON XII), Helsinki, Finland. Vartiainen, A. (ed). Outotec Oyj. pp. 293-301.

KLEYNHANS, E.L.J. 2011. Unique challenges of clay binders in a pelletised chromite pre-reduction process - a case study. MSc dissertation, NorthWest University, Potchefstroom, South Africa.

KLeynhans, E.L.J., Beukes, J.P., van Zyl, P.G., Kestens, P.H.I., and LANGa, J.M. 2012. Unique challenges of clay binders in a pelletised chromite prereduction process. Minerals Engineering, vol. 34. pp. 55-62. https://doi.org/10.1016/j.mineng.2012.03.021

Kleynhans, E.L.J., Neizel, B.W., BeuKes, J.P., and van Zyl, P.G. 2016. Utilisation of pre-oxidised ore in the pelletised chromite pre-reduction process. Minerals Engineering, vol. 92. pp. 114-124. https://doi.org/10.1016/j.mineng.2016.03.005

Kleynhans, E.L.J., BeuKes, J.P, van Zyl, P.G, and Fick, J.I.J. 2017. Technoeconomic feasibility of a pre-oxidation process to enhance prereduction of chromite. Journal of the Southern African Institute of Mining and Metallurgy, vol. 117 , no. 5. pp. 457-468.

http://dx.doi.org/10.17159/2411-9717/2017/v117n5a8

LindSLEY, D.H. 1991. Reviews in Mineralogy. Mineralogical Society of America. Washington DC. Vol. 25. pp. 323-350.

MotZer, W.E., and EngineERs, T. 2004. Chemistry, geochemistry, and geology of chromium and chromium compounds. Chromium(VI) Handbook. Guetin, J., Jacobs, J.A, and Avakian, C.P. (eds.). CRC Press. Boca Raton, FL. pp. 23-91.

Neizel, B.W., BeuKEs, J.P, van ZyL, P.G., and Dawson, N.F. 2013. Why is $\mathrm{CaCO}_{3}$ not used as an additive in the pelletised chromite pre-reduction process? Minerals Engineering, vol. 45. pp. 115-120. http://dx.doi.org/10.1016/j.mineng.2013.02.015

Ouтотес. 2017. Outotec® steel belt sintering plant. https://www.outotec.com/products/sintering-and-pelletizing/steel-beltsintering-plant [accessed 24 October 2017]

PäÄtalo, M. 2018. Head of Research and Development, Outokumpu, Finland. Personal communication.

PAKTUNC, A.D., and CABRI, L. 1995. A proton-and electron-microprobe study of gallium, nickel and zinc distribution in chromian spinel. Lithos, vol. 35, no. 3. pp. 261-282. https://doi.org/10.1016/0024-4937(95)99071-4

PAN, J., YANG, C., and ZHU, D. 2015. Solid state reduction of preoxidized chromite-iron ore pellets by coal. ISIJ International, vol. 55, no. 4 . pp. 727-735. http://doi.org/10.2355/isijinternational.55.727

RieккоLA-VANHANEn, M. 1999. Finnish expert report on best available techniques in ferrochromium production. Helsinki.

SCHNEIDER, T., and JENSEN, K.A. 2008. Combined single-drop and rotating drum dustiness test of fine to nanosize powders using a small drum. Annals of Occupational Hygiene, vol. 52, no. 1. pp. 23-34. https://doi.org/10.1093/annhyg/mem059

TAthavaKar, V.D., Antony, M., and JHA, A. 2005. The physical chemistry of thermal decomposition of South African chromite minerals. Metallurgical and Materials Transactions B, vol. 36, no. 1. pp. 75-84. https://doi.org/10.1007/s11663-005-0008-1

ZHAO, B. and HAyEs, P. 2010. Effects of oxidation on the microstructure and reduction of chromite pellets. Proceedings of the 12th International Ferro Alloys Congress (INFACON XII), Helsinki, Finland. Vartiainen, A. (ed). Outotec Oyj. pp. 263-273. 